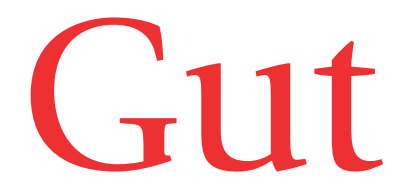

\title{
Editorial
}

\section{Gut in 1999}

Three years have elapsed since the current team took over the journal and we now feel that it is time for a change. Both Michael Arthur and Roger Chapman have expressed a desire to be released from their responsibilities as Associate Editors at the end of their three year term and reluctantly I have agreed to let them go. Michael and Roger have made outstanding contributions to the journal across the board but have particularly invigorated the liver and biliary sections. I am delighted to be able to announce that Professors Nick Wright and David Adams will be joining the editorial committee with responsibility for cancer and hepatobiliary disease, respectively. Both are leaders in their fields and I have no doubt that they will bring new insights and expertise to our fortnightly "hanging committee" meetings. The pattern of retirement and re-appointment will continue on a yearly basis such that two positions will become available each year. We believe that this will continuously revitalise the editorial process at Gut and avoid Associate Editor "burn-out". If you have the time, energy, enthusiasm, and expertise and would like to be considered for one of these positions in the future, do not hesitate to come forward.

We have also instigated a parallel process to renew the Editorial Board. All members were appointed initially for a three year term of office. However, to give stability and continuity to the Board, we have decided to release only a third of our members which makes it possible to begin a similar annual rolling renewal programme. Special thanks must go to all outgoing Board members for the support they have given Gut over the past three years. Board members are asked to attend two meetings a year and to play an active role in the strategic development of the journal. Most Board members are regular reviewers, make suggestions for leading articles and reviews, and act as Guest Editors from time to time. We are particularly delighted to welcome Marty Blaser, Bob Riddell, Derrick Martin, John Atherton, Emeran Mayer, Steve Collins, Tsutomu Chiba, and Nick LaRusso to the Board in 1999.

The two new sections of the journal, Science Alert and Clinical Alert, are now well underway and I am especially grateful to Tom MacDonald and Brian Haynes for the vital contributions that they have made in getting these sections started. A new column, The Gut Files, will appear in 1999 and will be brief accounts of important learning experi- ences in clinical practice. We have chosen to publish only a limited number of case reports which are generally restricted to those that illustrate an important advance in our understanding of disease pathogenesis or treatment. However, there are cases that do not fulfil these criteria but which constitute an important reminder for avoiding pitfalls in clinical practice. The Gut Files will not be a dumping ground for "pink canaries" and "fascinomas"! Guidance on the preparation of these brief articles can be found in the Instructions to Contributors which has now been revised. I also draw your attention to the fact that the length of original articles has been reduced from 4000 to 3500 words. This is partly to encourage conciseness but also to enable us to publish more papers.

During my second year as Editor I wrote an editorial, Research Misconduct. I am sorry to say that there has been no reduction in the number of papers that we receive that could, if published, amount to research fraud. Redundant publication, plagiarism and overt fraudulent manipulation of data continue to flow across the Editor's desk. We are indebted to our vigilant reviewers who in general have taken the lead in detecting research dishonesty. I continue to chair the Committee on Publication Ethics (COPE) which published its first report in 1998 and included our collective experience of cases of research misconduct. As editors we are becoming increasingly distressed by the frequency at which we detect research dishonesty and are highly concerned that this may represent just the tip of a rather large iceberg. In the past, editors have been reluctant to take further action when dishonesty is detected and publication prevented by rejection of a manuscript. Editors, however, have been accused of not doing enough to bring fraudsters to justice and the membership of COPE is now minded to report all incidences of research dishonesty to the Head of the author's institution, irrespective of whether the manuscript has been rejected or was published and subsequently found to be fraudulent. COPE is currently preparing guidelines on Good Publication Practice. We shall give formal notice in the journal once we have finalised our procedures for dealing with dishonest authors.

MICHAEL FARTHING fanuary 1999 